Revta brasil. Bot., São Paulo, V.24, n.2, p.135-143, jun. 2001

\title{
Potencial de infectividade de fungos micorrízicos arbusculares oriundos de área de caatinga nativa e degradada por mineração, no Estado da Bahia, Brasil ${ }^{1}$
}

\author{
GLADSTONE ALVES DA SILVA ${ }^{2}$, LEONOR COSTA MAIA ${ }^{2,4}$, FÁBIO SÉRGIO \\ BARBOSA DA SILVA ${ }^{2}$ e PAULO CÉSAR FERNANDES LIMA ${ }^{3}$
}

(recebido: 9 de fevereiro de 2000; aceito: 11 de janeiro de 2001)

\begin{abstract}
Infectivity potential of arbuscular mycorrhizal fungi present in area of native and mining disturbed "caatinga" in the state of Bahia, Brazil). The aims of this work were to quantify the spores and the most probable number of AMF propagules in soils from the Caraíba Mining, Bahia; to detect the effect of the season in the dynamics of AMF propagules and to determine the effects of mining on the potential of mycorrhizal infectivity. Soil samples were collected in the dry (August/98) and rainy seasons (February/99), from six subareas of the copper mining area: 1 - site that receives the waste product; 2 - the industrial area surroundings; 3 - low grade deposits; 4 - preserved "caatinga"; 5 - interface between the caatinga and the waste product area; 6 - site for extracting top soil for purpose of land filling. Thirty-two plant species were identified in the two meters around each collecting point. The highest diversity ( 21 species) occurred in the subarea 4, whereas the lowest plant diversity was observed in the subarea 3 (two species). The subareas 1 , 3 and 5 presented the least spore number $(<1$ per $\mathrm{g}$ of soil), possibly because of the high values of $\mathrm{Cu}$ and $\mathrm{Fe}$ and more alcaline $\mathrm{pH}$ in these soils. In general, spores density and number of infective propagules were low $(<2$ per $g$ of soil). There was no significant difference between number of spores in the dry and in the rainy seasons, except for the place 6 . However, there was variation between the sub areas, with significant differences in both seasons.
\end{abstract}

RESUMO - (Potencial de infectividade de fungos micorrízicos arbusculares oriundos de área de caatinga nativa e degradada por mineração, no Estado da Bahia, Brasil). Os objetivos deste trabalho foram quantificar o número de esporos e o número mais provável de propágulos infectivos de FMA em solos da mineradora Caraíba, verificando influências sazonais na dinâmica desses propágulos e determinando os efeitos da mineração sobre o potencial de infectividade micorrízica. Foram realizadas coletas de solo na estação seca (agosto/98) e na chuvosa (fevereiro/99), em seis sub áreas da mineradora de cobre: 1 - local onde é depositado o rejeito; 2 - arredores da área industrial; 3 - local onde são depositados restos de rocha com pouco minério; 4 - caatinga nativa, não impactada; 5 - interface entre a caatinga e o rejeito; 6 - local onde foi retirada a camada superficial do solo. Foram identificadas 32 espécies de plantas num raio de dois metros, a partir dos pontos de coleta de solo. Maior diversidade ( 21 espécies) foi encontrada na sub área 4 e menor ( 2 espécies) na sub área 3. As sub áreas 1, 3 e 5 apresentaram o menor número de esporos $(<1$ por $\mathrm{g}$ de solo), possivelmente devido aos elevados valores de $\mathrm{Cu}$ e $\mathrm{Fe}$ e ao $\mathrm{pH}$ mais alcalino. Em geral a densidade dos esporos e o número de propágulos infectivos foram baixos $(<2$ por g de solo). Não houve diferença significativa entre o número de esporos nas estações seca e chuvosa, a não ser para a sub área 6 . Entretanto, houve variação entre as sub áreas, com diferenças significativas nas duas estações do ano.

Key words - Arbuscular mycorrhiza, heavy metals, Glomales, mining, disturbed area

\section{Introdução}

As micorrizas arbusculares encontram-se amplamente distribuídas na maioria dos ecossistemas, desde os florestais aos desérticos, em regiões tropicais, temperadas e árticas e representam a mais ampla associação entre plantas e fungos encontrada na natureza (Souza \& Silva 1996). O

1. Parte da Dissertação de Mestrado de Gladstone Alves da Silva.

2. Universidade Federal de Pernambuco, Centro de Ciências Biológicas, Departamento de Micologia, Av. Prof. Nelson Chaves, s/n, 50 670-420 Recife, PE, Brasil.

3. Centro de Pesquisa Agropecuária do Trópico Semi-Árido (EMBRAPA - CPATSA), BR 428, km 152, 56300-000 Petrolina, PE, Brasil.

4. Autor para correspondência: leonorcmaia@hotmail.com caráter mutualista das micorrizas contribuiu para evolução e sobrevivência das plantas terrestres e dos fungos e existe desde há 400 milhões de anos (Smith $\&$ Read 1997). Apresentando pouca ou nenhuma especificidade hospedeira, os fungos micorrízicos arbusculares (FMA) constituem a regra na natureza (Harley 1989), atuando na definição de nichos ecológicos ocupados pelas plantas e na determinação da composição das comunidades vegetais (Francis \& Read 1995) e desempenhando importante papel no equilíbrio dessas comunidades (Harley 1989).

A micorriza é formada pela raiz hospedeira, o micélio intra-radicular (incluindo a interface simbiótica), o micélio extra-radicular (rede de hifas do solo) e os esporos (Merryweather \& Fitter 1998), influindo na associação fatores do solo, do hospedeiro e do fungo. Sendo assim, a perturbação 
do solo pode causar impacto na micorrização, dependendo de mudanças das condições do solo, da natureza dos propágulos fúngicos e da vegetação presente (Brundrett et al. 1996). Do mesmo modo, a infectividade de FMA em solos de vários ecossistemas pode ser diminuída pela perturbação do solo (Jasper et al. 1994).

Em áreas de mineração, a retirada da vegetação natural, a intensa movimentação do solo e o acréscimo de considerável volume de rejeitos, elevando, em alguns casos, o nível de metais pesados no solo, contribuem para o distúrbio do local (Souza \& Silva 1996), causando grande impacto sobre os microrganismos, a vegetação e os processos funcionais do ecossistema (Valsecchi et al. 1995). Estudos em regiões perturbadas pela extração mineral mostraram que, em várias dessas áreas, os FMA foram reduzidos ou eliminados (Allen 1991). Nível adequado de infectividade de FMA no solo, depois da mineração, é importante para o sucesso do restabelecimento da diversidade vegetal na formação de um ecossistema auto-sustentável (Jasper et al. 1994). Entretanto, antes que micorrizas sejam utilizadas na revegetação de áreas degradadas por mineração, é necessário saber a condição micorrízica das espécies de plantas que ocorrem naturalmente nos ecossistemas sem distúrbio (Bellgard 1991), quais fungos estão envolvidos na formação da micorriza (Merryweather \& Fitter 1998), o grau de colonização radicular em solos contaminados, o papel fisiológico dos FMA no aporte e translocação de metais pesados nas plantas e a implicação ecológica da presença ou não dos FMA atuando sobre a seleção e sobrevivência das plantas hospedeiras (Griffioen et al. 1994).

Algumas técnicas utilizando a colonização radicular ou o número de esporos têm sido empregadas para enumerar os propágulos infectivos de FMA no solo. Sieverding (1991) sugere que os níveis de colonização micorrízica podem variar de acordo com a espécie de planta, as condições do solo e as espécies de FMA presentes no local. O grau de colonização é uma estimativa da biomassa fúngica dentro da raiz, não de propágulos infectivos no campo e a correlação entre grau de colonização e propágulos infectivos é raramente encontrada. Ainda segundo esse autor, a simples contagem de esporos serviria apenas para enumerar os propágulos infectivos de FMA no solo sob certas circunstâncias, tais como após longo período sem vegetação, ou depois de longa estação seca e só pode ser relacionada ao potencial de infectividade se for conhecida a condição dos esporos, ou seja, se estão vivos, mortos ou dormentes (Liu \& Luo 1994).

A técnica do número mais provável (NMP) enumera todos os propágulos que têm habilidade para colonizar a planta hospedeira, falhando apenas na detecção de esporos dormentes (An et al. 1990, Sieverding 1991, Liu \& Luo 1994). Esta técnica é baseada na avaliação dos propágulos infectivos em diluições seriadas até sua extinção. Porém, segundo Wilson \& Trinick (1982), embora forneça dados úteis sobre a infectividade dos FMA, as estimativas obtidas são muito dependentes das condições experimentais utilizadas.

Poucos são os trabalhos sobre a ocorrência de FMA em ecossistemas naturais no Brasil. De acordo com a vegetação, Trufem (1996) menciona trabalhos na província amazônica, província atlântica e cerrado, sem registro para a caatinga e os pampas. No Nordeste são encontrados apenas os trabalhos de Maia \& Trufem (1990) e Melo et al. (1997) relatando a diversidade de FMA em áreas cultivadas com plantas de interesse agronômico, no Estado de Pernambuco.

Os objetivos deste trabalho foram determinar os efeitos da mineração sobre o potencial de infectividade de FMA, através da quantificação do número de esporos, por contagem direta, e do número de propágulos infectivos de FMA no solo, pela técnica do NMP, verificando influências sazonais na dinâmica dos propágulos de FMA.

\section{Material e métodos}

Área de estudo - A mineração Caraíba localiza-se em Pilar, município de Jaguarari, Estado da Bahia (latitude 9 51 '43” S e longitude $39^{\circ} 53^{\prime} 50^{\prime}$ ” W). O componente extraído como minério é o cobre $(\mathrm{Cu})$. A região apresenta precipitação anual de $400 \mathrm{~mm}$, com chuvas ocorrendo principalmente nos meses de novembro a abril e temperatura média de $25^{\circ} \mathrm{C}$. Tem como vegetação predominante a caatinga e solos dos tipos areno-argiloso e argiloso, sendo o clima tropical semi-árido (dados fornecidos pela Mineração Caraíba).

Coletas - As coletas foram realizadas em duas épocas: uma na estação seca, (agosto/98) e outra na estação chuvosa (fevereiro/99), em seis sub áreas da mineradora; cinco apresentavam distúrbios ambientais provocados pela atividade mineradora e uma apresentava área de caatinga preservada, sendo 
esta considerada como controle. Em cada sub área foram coletadas sete amostras de solo (de cinco a $20 \mathrm{~cm}$ de profundidade) preferencialmente na rizosfera de plantas, sendo os pontos definidos aleatoriamente. Em cada ponto de coleta do solo foi considerado um raio de $2 \mathrm{~m}$, onde foram registradas as espécies vegetais arbóreas/arbustivas e herbáceas ocorrentes.

Identificação das plantas - As plantas encontradas próximas aos pontos de coleta foram identificadas por equipe da EMBRAPA/CPATSA.

Caracterização das sub áreas - Sub área 1 - Compreende a bacia de rejeito da mineradora, constituído por pó da rocha da qual se extrai o minério. $\mathrm{O}$ local apresentou-se totalmente desprovido de espécies vegetais durante a estação seca, porém algumas surgiram durante a estação chuvosa. Sub área 2 - Compreende os arredores da mineradora propriamente dita, ou seja, a área do perímetro industrial, caracterizada pela ausência da maioria das espécies nativas da caatinga. No local foram encontrados vários espécimes de algaroba (Prosopis juliflora), que parece estar colonizando o ambiente como pioneira, de vegetação secundária, depois da retirada das plantas nativas. Sub área 3 - Local onde são depositados restos de rocha com pouco ou nenhum minério cobertos por fina camada de solo proveniente de outro local. O material depositado chega a formar pilhas de até cerca de $20 \mathrm{~m}$ de altura em determinados locais. Foram observados alguns espécimes de algaroba e fumo-bravo (Nicotiana glauca), com distribuição espaçada no local. Sub área 4 - Com diversidade vegetal própria da caatinga, está preservada, sendo constituída principalmente por plantas nativas da região (sub área controle). Sub área 5 - Compreende a interface entre a bacia de rejeito e a caatinga. Nesta região foram encontradas algumas plantas em decomposição e outras apresentando sinais de ressecamento e perda das folhas. O local apresentava uma camada de rejeito de 20 a $50 \mathrm{~cm}$, sobre o solo natural. Sub área 6 - Local onde é retirada a camada superficial do solo para compor a região onde são depositados os restos de rocha sem minério.

Análise do solo - A análise do solo da área de mineração, oriundo da primeira coleta, foi realizada pelo Laboratório de Solos da EMBRAPA/CPATSA; o solo usado como diluente foi analisado no IPA, ambos processados segundo EMBRAPA (1997) (tabela 1)

Tabela 1. Análise química e granulométrica do solo em seis sub áreas da Mineração Caraíba, Jaguarari, Bahia, e do solo usado como diluente no método do NMP. 1 = bacia de rejeito; 2 = perímetro industrial; $3=$ local onde são depositados restos de rocha com pouco minério; 4 = caatinga; $5=$ interface entre a caatinga e a bacia de rejeito; $6=$ local onde foi retirada a camada superficial do solo.* $=\mathrm{P}$ disponível, pelo método de Mehlich (EMBRAPA 1997). Os dados são médias de sete pontos de coleta para cada sub área, exceto a 1 e o solo diluente.

\begin{tabular}{|c|c|c|c|c|c|c|c|c|c|c|c|c|c|}
\hline \multirow[t]{2}{*}{ Sub áreas } & $\mathrm{P}^{*}$ & $\mathrm{Cu}$ & $\mathrm{Mn}$ & $\mathrm{Zn}$ & $\mathrm{Fe}$ & $\mathrm{K}$ & $\mathrm{Mg}$ & $\mathrm{Ca}$ & $\mathrm{Al}$ & \multirow{2}{*}{$\frac{\mathrm{pH}\left(\mathrm{H}_{2} \mathrm{O}\right)}{1: 2,5}$} & \multicolumn{3}{|c|}{ Granulometria (\%) } \\
\hline & \multicolumn{5}{|c|}{$\mathrm{cmol} \cdot \mathrm{dm}^{-3}$} & \multicolumn{4}{|c|}{ meq. $100 \mathrm{~g}^{-1}$ de solo } & & Areia & Silte & Argila \\
\hline 1 & 266 & 433,4 & 53,4 & 5,7 & 434,4 & 0,06 & 1,4 & 5,2 & 0,00 & 8,2 & 93 & 3 & 4 \\
\hline 2 & 44 & 86,2 & 33,4 & 2,0 & 65,9 & 0,25 & 5,9 & 10,5 & 0,04 & 6,9 & 60 & 24 & 16 \\
\hline 3 & 167 & 606,7 & 44,0 & 5,2 & 168,1 & 0,27 & 5,9 & 7,1 & 0,01 & 7,3 & 69 & 21 & 10 \\
\hline 4 & 141 & 2,7 & 46,4 & 2,2 & 33,6 & 0,30 & 3,7 & 8,0 & 0,05 & 6,2 & 62 & 24 & 14 \\
\hline 5 & 179 & 445,4 & 47,8 & 5,0 & 337,1 & 0,61 & 1,8 & 6,0 & 0,00 & 7,8 & 61 & 35 & 4 \\
\hline 6 & 95 & 30,4 & 48,6 & 1,6 & 52,4 & 0,22 & 5,4 & 9,4 & 0,17 & 7,1 & 65 & 19 & 16 \\
\hline Solo diluente & 2 & - & - & - & - & 0,15 & 1,8 & 0,9 & 0,70 & 4,7 & 43 & 36 & 21 \\
\hline
\end{tabular}

Potencial de infectividade do solo - O potencial de infectividade do solo foi definido a partir do método do Número Mais Provável (NMP) de propágulos (Sieverding 1991). Para cada sub área foi usada uma amostra composta (sete pontos diferentes) de solo do campo, homogeneizado, seco, não esterilizado e peneirado (malha de $0,5 \mathrm{~cm}$ de abertura), sendo esta a amostra base para as diluições (solo A). O solo usado nas diluições (solo B), proveniente do Município de São João (PE), com vegetação típica de caatinga, era do tipo podzólico vermelho-amarelo. Este solo foi seco, autoclavado e peneirado (malha de $0,5 \mathrm{~cm}$ de abertura), 10 dias antes de ser usado.

Em cada vaso de $250 \mathrm{~mL}$ de capacidade foram colocados $150 \mathrm{~g}$ do solo B, $50 \mathrm{~g}$ do substrato de diluição (solo A + solo B) $\mathrm{e}$, por cima, $50 \mathrm{~g}$ do solo $\mathrm{B}$. Como planta isca foi usada painço (Panicum miliaceum L.). Após a emergência das plântulas fez-se o desbaste, sendo mantidas apenas cinco por vaso. Para determinação do NMP, as plântulas foram colhidas após seis semanas, sendo as raízes coradas (Phillips \& Hayman 1970) e observadas ao microscópio para verificação da presença ou não de associação micorrízica. Foi considerada colonizada a planta que apresentou ao menos duas das seguintes estruturas próprias de FMA: hifas, arbúsculos, vesículas ou esporos. Foram feitas nove diluições sucessivas na proporção de 1:3 (solo do (1/262144), sendo usadas cinco repetições por diluição.

Para cálculo do NMP foi usada a seguinte equação:

$\log \Omega=$ x.log a $-\mathrm{K}$

onde: $\Omega$ é o número de propágulos infectivos; x é o número médio de potes com plantas infectadas; portanto, $\mathrm{x}=$ número total de potes com plantas infectadas dividido pelo número de replicatas por diluição. K é encontrado na tabela VIII de Fisher \& Yates (1970) pelos valores determinados de x ou y (Sieverding 1991).

$$
\mathrm{y}=\mathrm{s}-\mathrm{x}
$$

onde: y define o valor de K; s é o número de níveis de diluição (onde $4^{0}$ é o primeiro nível) sendo a o fator de diluição, que foi 4 no presente trabalho.

Contagem dos esporos - Os esporos foram retirados dos solos dos sete pontos de coleta de cada sub área pelo método do peneiramento úmido (Gerderman \& Nicolson 1963), seguido por campo/solo esterilizado), com os níveis de diluição de $4^{0}$ até $4^{-9}$ 
centrifugação e flutuação em sacarose a $40 \%$ (Jenkins 1964). O material obtido foi colocado em placas de Petri canaletadas para contagem direta dos esporos, com auxílio de estereomicroscópio (Zeiss - 40x).

Análise estatística - Os dados de densidade de esporos, transformados por $\log (\mathrm{x}+1)$ como sugerido por Sieverding (1991), foram submetidos à análise de variância, sendo as médias comparadas pelo teste de Duncan $(\mathrm{P} \leq 5 \%)$. O número de esporos, de acordo com a variação sazonal para cada sub área, foi comparado pelo teste $t$ a 5\%. Também foi realizada análise de correlação entre os dados de esporos e os níveis de $\mathrm{Fe}$ e $\mathrm{Cu}$, todos transformados por $\log (\mathrm{x}+1)$ e de $\mathrm{pH}$, através do coeficiente de correlação de Pearson a $1 \%$. Todas as análises foram feitas usando-se o programa Statistica (Statsoft 1995).

\section{Resultados e Discussão}

Foram identificadas 32 espécies de plantas, considerando todos os pontos de coleta (tabela 2). A atividade mineradora causou sérios danos ao local, o que foi observado pelas baixas diversidade vegetal e quantidade de esporos de FMA (tabelas 2,3) nas cinco sub áreas afetadas, principalmente quando comparadas com a sub área apresentando caatinga preservada (sub área 4). Estudos em regiões perturbadas pela extração mineral demonstram que, em muitas dessas áreas, os FMA foram reduzidos ou eliminados e que muitas espécies de plantas importantes foram dependentes das micorrizas para o seu estabelecimento e sobrevivência (Allen 1991).

Em geral, o número de esporos encontrados para cada sub área foi baixo, sempre inferior a 160/100 g de solo, não sendo observada diferença estatística, pelo teste $t$, entre o número de esporos na estação seca e chuvosa, a não ser para a sub área 6 . Entretanto, houve grande variação entre as sub áreas, com diferenças significativas tanto na estação seca, quanto na chuvosa (tabela 3). Em Pernambuco, Melo et al. (1997) encontraram 15 espécies de FMA associadas a raízes de bananeiras, observando que a densidade de esporos variou de 44 a 271/100 g de solo e Maia \& Trufem (1990) relataram 24 espécies de FMA na rizosfera de plantas de interesse agronômico, tendo observado que o número total de esporos variou, de acordo com a planta hospedeira, de 26 a 437/100 g de solo.

A análise do solo revelou elevados teores de $\mathrm{P}$, $\mathrm{Cu}$ e $\mathrm{Fe}$ em algumas sub áreas (tabela 1). Os dados mostraram correlação negativa significante entre os níveis de $\mathrm{Cu}, \mathrm{Fe}$ e $\mathrm{pH}$ e o número de esporos (tabela 4). Possivelmente as sub áreas 1, 3 e 5 apresentaram menor número de esporos devido aos elevados valores de $\mathrm{Cu}$ e $\mathrm{Fe}$ e ao $\mathrm{pH}$ alcalino desses locais. De acordo com Nogueira (1996), além do efeito tóxico direto nas plantas, o excesso de metais é prejudicial aos FMA; vários metais pesados são fungitóxicos, reduzindo a germinação dos esporos, o crescimento micelial e, conseqüentemente, a colonização micorrízica. Trabalhando em solos contaminados por $\mathrm{Cu}$, Griffioen et al. (1994) encontraram apenas três, de 12 amostras de raízes de Agrostis capillaris L., colonizadas por FMA; mesmo assim, essas raízes apresentavam baixo nível de colonização (1, 3 e $10 \%$ ). Os autores sugeriram que a ausência de colonização por FMA no local seria devido à atividade fungitóxica desse metal.

De modo geral, o número de esporos no solo foi sempre superior ao número de propágulos infectivos, a não ser para a sub área 1, durante a época chuvosa (tabela 3 ). Isso pode ter ocorrido por serem os esporos estruturas mais resistentes que outros tipos de propágulos, como hifas e vesículas, podendo permanecer no solo por mais tempo. Também é possível que esporos inviáveis tenham sido contados; além disso, algumas espécies de FMA apresentam dormência e nesse caso não são detectadas pela técnica do NMP. Embora em algumas circunstâncias a densidade de esporos possa apresentar correlação com o total de propágulos infectivos de FMA, em outras nenhuma correlação é observada (Sieverding 1991). Avaliando os métodos do NMP e de contagem direta de esporos, An et al. (1990) mencionaram que, dependendo da espécie de FMA, o número de esporos pode ser maior ou menor que o de propágulos realmente infectivos.

Das seis sub áreas analisadas, a 1 foi a única que não apresentou esporos, quaisquer outros propágulos infectivos ou mesmo fragmentos de raízes colonizadas nas amostras de solo coletadas durante a estação seca. No entanto, foi evidenciada a presença de esporos, por contagem direta, e de outros propágulos infectivos de FMA, nas amostras coletadas na estação chuvosa. Não foram encontradas plantas na bacia de rejeito durante a coleta no período seco, porém durante a época das chuvas foram observadas, principalmente, algumas plantas herbáceas, sendo listadas quatro espécies. É possível que a presença de plantas durante a estação 
Tabela 2. Espécies de plantas existentes num raio de dois metros a partir dos pontos de coleta, em sub áreas da Mineração Caraíba, Jaguarari, Bahia. 1 = bacia de rejeito; 2 = perímetro industrial; 3 = local onde são depositados restos de rocha com pouco minério; 4 = caatinga; 5 = interface entre a caatinga e a bacia de rejeito; $6=$ local onde foi retirada a camada superficial do solo.

\begin{tabular}{|c|c|c|c|c|c|c|}
\hline \multirow[t]{2}{*}{ Família/espécie } & \multicolumn{6}{|c|}{ Sub áreas } \\
\hline & $1 *$ & 2 & 3 & 4 & 5 & 6 \\
\hline \multicolumn{7}{|l|}{ ANACARDIACEAE } \\
\hline Myracrodruon urundeuva Allem. & & & & & $\mathrm{X}$ & \\
\hline Schinopsis brasiliensis Engl. & & & & $\mathrm{X}$ & & \\
\hline Spondias tuberosa Arruda & & & & $\mathrm{X}$ & $\mathrm{X}$ & \\
\hline \multicolumn{7}{|l|}{ BROMELIACEAE } \\
\hline Neoglaziovia variegata $\mathrm{Mez}$ & & & & $\mathrm{X}$ & $\mathrm{X}$ & \\
\hline Eucholirium spectabile Mart. & & & & $\mathrm{X}$ & & \\
\hline \multicolumn{7}{|l|}{ BURSERACEAE } \\
\hline Commiphora leptophloeos (Mart.) Gillet & & & & $\mathrm{X}$ & & \\
\hline \multicolumn{7}{|l|}{ BYTTNERIACEAE } \\
\hline Melochia tomentosa $\mathrm{L}$. & & $\mathrm{X}$ & & $\mathrm{X}$ & $\mathrm{X}$ & $\mathrm{X}$ \\
\hline \multicolumn{7}{|l|}{ CACTACEAE } \\
\hline Opuntia palmadora Briton \& Rose & & & & $\mathrm{X}$ & & \\
\hline Cereus jamaracu DC. & & $\mathrm{X}$ & & & & \\
\hline Pilosocereus gounellei (Weber) Byl. \& Rowl & & $\mathrm{X}$ & & $\mathrm{X}$ & $\mathrm{X}$ & \\
\hline \multicolumn{7}{|l|}{ CAESALPINACEAE } \\
\hline Caesalpinia pyramidalis Tul. & & & & $\mathrm{X}$ & & \\
\hline \multicolumn{7}{|l|}{ CAPPARIDACEAE } \\
\hline Cleone spinosa Jacq. & $\mathrm{X}$ & & & & & $\mathrm{X}$ \\
\hline \multicolumn{7}{|l|}{ COMBRETACEAE } \\
\hline Ruprechtia apetala Wedd. & & & & $\mathrm{X}$ & $\mathrm{X}$ & \\
\hline \multicolumn{7}{|l|}{ EHRETIACEAE } \\
\hline Cordia leucocephalla Moric. & & & & $\mathrm{X}$ & & \\
\hline \multicolumn{7}{|l|}{ EUPHORBIACEAE } \\
\hline Jatropha molissima Pohl & $\mathrm{X}$ & $\mathrm{X}$ & & $\mathrm{X}$ & $\mathrm{X}$ & $\mathrm{x}$ \\
\hline Cnidosculus urens (L.) Arthur & & & & $\mathrm{X}$ & $\mathrm{X}$ & \\
\hline Cnidosculus phyllacanthus Pax \& K. Hoffman & & $\mathrm{X}$ & & $\mathrm{X}$ & $\mathrm{X}$ & \\
\hline Manihot pseudoglaziovii Pax \& K. Hoffman & & & & $\mathrm{x}$ & & \\
\hline Croton sonderianus Muell. Arg. & & & & $\mathrm{X}$ & & \\
\hline Jatropha ribifolia (Pohl) Baill. & & & & & & $\mathrm{X}$ \\
\hline Croton campestris (St. Hil.) Muell. Arg. & & $\mathrm{X}$ & & $\mathrm{X}$ & & \\
\hline \multicolumn{7}{|l|}{ MALVACEAE } \\
\hline Gaya sp. & $\mathrm{X}$ & $\mathrm{X}$ & & $\mathrm{X}$ & $\mathrm{X}$ & $\mathrm{X}$ \\
\hline Sida cordifolia $\mathrm{L}$. & & & & & & $\mathrm{X}$ \\
\hline Herissantia tiubae (K. Schum.) Briz. & & & & & & $\mathrm{x}$ \\
\hline \multicolumn{7}{|l|}{ MIMOSACEAE } \\
\hline Prosopis juliflora (Sw.) DC. & & $\mathrm{X}$ & $\mathrm{X}$ & & & $\mathrm{X}$ \\
\hline
\end{tabular}


(cont.)

\begin{tabular}{|c|c|c|c|c|c|c|}
\hline \multirow[t]{2}{*}{ Família/espécie } & \multicolumn{6}{|c|}{ sub áreas } \\
\hline & $1 *$ & 2 & 3 & 4 & 5 & 6 \\
\hline Anadenanthera macrocarpa (Benth.) Brenan & & & & $\mathrm{X}$ & & \\
\hline Mimosa arenosa (Willd.) Poir. & & & & & $\mathrm{X}$ & \\
\hline Mimosa sp. & & & & $\mathrm{X}$ & & \\
\hline Calliandra depauperata Benth. & & & & & $\mathrm{X}$ & \\
\hline \multicolumn{7}{|l|}{ SOLANACEAE } \\
\hline Nicotiana glauca Graham & $\mathrm{X}$ & & $\mathrm{X}$ & & $\mathrm{X}$ & $\mathrm{X}$ \\
\hline \multicolumn{7}{|l|}{ CAPPARACEAE } \\
\hline Capparis yco Eichl. & & & & $\mathrm{X}$ & & \\
\hline \multicolumn{7}{|l|}{ APOCYNACEAE } \\
\hline Aspidosperma pirifolium Mart. & & & & & $\mathrm{X}$ & \\
\hline Total & $4 *$ & 8 & 2 & 21 & 14 & 9 \\
\hline
\end{tabular}

*Plantas encontradas apenas na segunda coleta.

Tabela 3. Número médio de esporos e número mais provável (NMP) de propágulos infectivos de FMA/100 g de solo em sub áreas da Mineração Caraíba, Jaguarari, Bahia, de acordo com a época de coleta. Médias seguidas pela mesma letra, minúsculas nas colunas e maiúsculas nas linhas, não diferem significativamente entre si pelo teste de Duncan e teste $t$ a 5\%, respectivamente. $1=$ bacia de rejeito; $2=$ perímetro industrial; $3=$ local onde são depositados restos de rocha com pouco minério; 4 $=$ caatinga; $5=$ interface entre a caatinga e a bacia de rejeito; $6=$ local onde foi retirada a camada superficial do solo. $*$ = média de sete pontos de coleta.

\begin{tabular}{lcrlcc}
\hline Sub áreas & \multicolumn{2}{c}{ Estação seca } & & \multicolumn{2}{c}{ Estação chuvosa } \\
\cline { 2 - 3 } \cline { 5 - 6 } & $\begin{array}{c}\mathrm{n}^{\circ} \text { de } \\
\text { esporos* }\end{array}$ & NMP & & $\begin{array}{c}\text { n }{ }^{\circ} \text { de } \\
\text { esporos* }\end{array}$ & NMP \\
\hline 1 & $0 \mathrm{cA}$ & 0,00 & & $1 \mathrm{dA}$ & 1,60 \\
2 & $87 \mathrm{aA}$ & 8,96 & & $86 \mathrm{abA}$ & 1,10 \\
3 & $19 \mathrm{bA}$ & 1,10 & & $12 \mathrm{cdA}$ & 2,20 \\
4 & $151 \mathrm{aA}$ & 15,64 & & $126 \mathrm{aA}$ & 5,12 \\
5 & $17 \mathrm{bA}$ & 0,00 & & $51 \mathrm{bcA}$ & 6,78 \\
6 & $106 \mathrm{aA}$ & 35,92 & & $32 \mathrm{abcB}$ & 27,22 \\
\hline
\end{tabular}

chuvosa tenha propiciado a detecção de propágulos de FMA nesse local.

Segundo Fischer et al. (1994), os FMA podem ser indispensáveis ao estabelecimento e crescimento de algumas plantas em certos ambientes. De acordo com Allen et al. (1998), a presença dos FMA em áreas degradadas pode estar relacionada com a cobertura vegetal, ou seja, pode depender das plantas presentes no local. O término das atividades de deposição de rejeito entre uma estação e outra também pode ter propiciado a melhoria das condições do local, facilitando assim a presença dos FMA. O acréscimo de considerável volume de rejeitos contribui para o distúrbio de áreas de mineração (Souza \& Silva 1996).

Na sub área 5 foram observadas 14 espécies de plantas e alguns esporos de FMA. Embora esporos estivessem presentes, não foram detectados propágulos infectivos durante a primeira coleta; entretanto, na segunda coleta (estação chuvosa), foram evidenciados alguns propágulos infectivos de FMA. Da mesma forma que o observado na sub área 1 , é possível que o crescimento de plantas herbáceas e a suspensão da deposição do rejeito tenham propiciado condições favoráveis para a detecção de propágulos infectivos de FMA durante a estação chuvosa.

A sub área 2 também apresentou baixa diversidade vegetal quando comparada com a de caatinga, tendo sido listadas apenas oito espécies, com abundância de algaroba. Nas sub áreas 2 e 4, o número de esporos não variou entre uma estação e outra, porém o de propágulos infectivos foi reduzido durante a estação chuvosa. É possível que a presença de esporos apresentando dormência tenha mascarado a análise do NMP de propágulos infectivos na época chuvosa, já que não houve 
Tabela 4. Coeficiente de correlação de Pearson (r) entre número de esporos, na estação seca e chuvosa, e níveis de $\mathrm{Fe}, \mathrm{Cu}$ e pH. * = correlação significativa $(\mathrm{P}=0,01)$.

\begin{tabular}{lcc}
\hline \multirow{2}{*}{ Variáveis } & \multicolumn{2}{c}{ Esporos } \\
\cline { 2 - 3 } & estação seca & estação chuvosa \\
\hline Cobre & $-0,57^{*}$ & $-0,49^{*}$ \\
Ferro & $-0,55^{*}$ & $-0,48^{*}$ \\
$\mathrm{pH}$ & $-0,70^{*}$ & $-0,54^{*}$ \\
\hline
\end{tabular}

diferença significativa no número de esporos entre a primeira e a segunda estação.

Trabalhando com a dinâmica sazonal de FMA em uma floresta tropical decídua, Allen et al. (1998) observaram que a colonização e esporulação durante a estação chuvosa eram maiores do que na estação seca, sugerindo que isso ocorria devido à maior atividade micorrízica naquele período, em conseqüência da maior quantidade de raízes na camada mais superficial do solo nessa estação.

$\mathrm{Na}$ sub área 6, onde foram registradas nove espécies de plantas, foi encontrado o maior número de propágulos infectivos no solo. No entanto, durante a estação chuvosa houve decréscimo significativo do número de esporos. A quantidade de raízes colonizadas por um FMA pode mudar através das estações (Rosendahl et al. 1989). A dinâmica da formação de micorriza, individualmente (por fungo), varia devido às diferenças no crescimento de hifas, da taxa intrínseca de colonização dos propágulos e da capacidade do fungo para usar o carbono das raízes hospedeiras (Abbott \& Gazey 1994). Muitas plantas da sub área 6 morreram entre a primeira e a segunda coletas, possivelmente devido à erosão causada pela chuva. A diminuição do número de espécimes vegetais, observada na estação chuvosa, pode ter sido a causa da diminuição do número de propágulos de FMA presentes no solo.

Na sub área 3 foi observada a ocorrência de apenas duas espécies de plantas nos pontos de coleta. Também se constatou baixo número de esporos e de propágulos infectivos, não sendo observadas diferenças nesses números, entre as estações seca e chuvosa.

A sub área 4 apresentou o maior número de espécies vegetais (21). No entanto, ao contrário do que se esperava, esse local com caatinga preservada não foi o que apresentou maior número de propágulos infectivos. Na sub área 6 foram encontrados mais propágulos infectivos nos dois períodos de coleta, embora o número de esporos tenha sido inferior ao encontrado na sub área 4.

Fischer et al. (1994) observaram que o número de propágulos micorrízicos foi baixo $(0,6-10,2 / 100$ $\mathrm{g}$ de solo) em uma área de floresta tropical secundária, além de ser semelhante ao encontrado em dois locais mantidos por mais de quatro anos sem vegetação. Os autores encontraram níveis mais elevados de propágulos infectivos (56,7-62,8/100 g de solo) em local com vegetação composta principalmente por gramíneas. A sub área 6 apresentava muitos espécimes de algaroba, o que poderia explicar o potencial de infectividade de FMA mais alto nesse local. Além disso, o solo da sub área 4 apresentou nível de $\mathrm{P}$ bem mais alto do que $\mathrm{o}$ da sub área 6 , o que pode ter inibido o desenvolvimento de propágulos micorrízicos. Trabalhando com a aplicação de $\mathrm{P}$ em plantas de Paspalum notatum Flügge colonizadas com Gigaspora margarita Becker \& Hall, Douds (1994) observou que o incremento de $\mathrm{P}$ diminuiu a colonização radicular das plantas e a produção de esporos pelo fungo. Esse fato ajudaria a explicar o menor número de propágulos infectivos na caatinga preservada, em relação ao encontrado na sub área 6.

Deve ser considerado que algumas plantas que estavam na interface caatinga-rejeito morreram entre a primeira e a segunda coletas, porém nasceram algumas herbáceas. A vegetação da caatinga não está resistindo ao impacto causado pela mineração, porém plantas arbóreas exóticas (algaroba) e algumas herbáceas nativas (fumo-bravo, malva [Gaya sp.]) começam a tomar conta da região degradada, atuando como plantas pioneiras.

Segundo Jasper et al. (1994), adequado nível de infectividade de FMA no solo, após a mineração, é provavelmente um dos importantes componentes para o sucesso do restabelecimento da diversidade vegetal e a formação de ecossistema auto-sustentável.

Trabalhando com a avaliação da influência dos adubos verdes sobre o potencial de inóculo de FMA indígenas, Espíndola et al. (1998) observaram que tanto o número de esporos quanto o de outros propágulos de FMA foi sempre menor nos tratamentos sem vegetação, aumentando porém com 
o uso da adubação verde. De acordo com o observado, recomenda-se que um processo de revegetação das áreas acometidas seja iniciado. Mudas micorrizadas podem ser usadas, pois o potencial de infectividade por FMA foi baixo na maioria das áreas estudadas. É importante que seja promovida a revegetação do local para manutenção ambiental da diversidade, tanto vegetal e animal, quanto microbiana. Assim, considerando a recomendação de Dias et al. (1995), seria interessante usar leguminosas (nativas ou não) noduladas e micorrizadas para os processos iniciais de recuperação da área, pois além de ser menos oneroso do que os modelos tradicionais de recuperação, essas plantas têm excelente capacidade de adaptação e produzem grande biomassa.

Agradecimentos: Aos Laboratórios de Solos do Centro de Pesquisa Agropecuária do Trópico Semi-Árido (EMBRAPA-CPATSA) e do IPA, pelas análises de solo. À Mineração Caraíba, pelo apoio nas coletas. À CAPES e ao CNPq, pelas bolsas concedidas respectivamente a G.A. Silva (PG), L.C. Maia (pesq.) e F.S.B. Silva (PIBIC/UFPE). A Orivaldo José Saggin-Júnior, pela ajuda nas coletas e fornecimento de material bibliográfico. A Sandra Trufem, Uided Cavalcante e Andrea Pedrosa, pelo material bibliográfico fornecido e, especialmente, pelas críticas e sugestões.

\section{Referências bibliográficas}

ABBOTT, L.K \& GAZEY, C. 1994. An ecological view of the formation of VA mycorrhizas. Plant and Soil 159:69-78.

ALLEN, M.F. 1991. The ecology of mycorrhizae. Cambridge University Press, Cambridge.

ALLEN, E.B., RINCÓN, E., ALLEN, M.F., PÉREZ-JIMENEZ, A. \& HUANTE, P. 1998. Disturbance and seasonal dynamics of mycorrhizae in a tropical deciduous forest in Mexico. Biotropica 30:261-274.

AN, Z.Q., HENDRIX, J.W., HERSHMAN, D.E. \& HENSON, G.T. 1990. Evaluation of the "most probable number" (MPN) and wet-sieving methods for determining soil-borne populations of endogonaceous mycorrhizal fungi. Mycologia 82:576-581.

BELLGARD, S.E. 1991. Mycorrhizal associations of plant species in Hawkesbury Sandstone vegetation. Australian Journal of Botany 39:357-364.

BRUNDRETT, M.C., ASHWATH, N. \& JASPER, D.A. 1996. Mycorrhizas in the Kakadu region of tropical Australia. II. Propagules of mycorrhizal fungi in disturbed habitats. Plant and Soil 184:173-184.

DIAS, L.E., FRANCO, A.A., CAMPELLO, E., FARIA, S.M. \& SILVA, E.M. 1995. Leguminosas forestales: aspectos relacionados com su nutrición y uso en la recuperación de suelos degradados. Bosque 16:121-127.
DOUDS, D.D. 1994. Relationship between hyphal and arbuscular colonization and sporulation in a mycorrhiza of Paspalum notatum Flügge. New Phytologist 126:233-237.

EMBRAPA. 1997. Manual de métodos de análise de solo. 2 ed. EMBRAPA, Rio de Janeiro.

ESPINDOLA, J.A.A., ALMEIDA, D.L., GUERRA, J.G.M., SILVA, E.M.R. \& SOUZA, F.A. 1998. Influência da adubação verde na colonização micorrízica e na produção da batata-doce. Pesquisa Agropecuária Brasileira 33:339-347.

FISCHER, C.R., JANOS, D.P., PERRY, D.A., LINDERMAN, R.G. \& SOLLINS, P. 1994. Mycorrhiza inoculum potentials in tropical secondary succession. Biotropica 26:369-377.

FISHER, R.A. \& YATES, F. 1970. Statistical tables for biological, agricultural and medical research. 6 ed. Hafner Publication Company, Davien.

FRANCIS, R. \& READ, D.J. 1995. Mutualism and antagonism in the mycorrhizal symbiosis, with special reference to impacts on plant community structure. Canadian Journal of Botany 73 (Supp.1):1301-1309.

GERDERMAN, J.W. \& NICOLSON, T.H. 1963. Spores of mycorrhizal Endogone species extracted from soil by wet sieving and decanting. Transactions of the British Mycological Society 46:235-244.

GRIFFIOEN, W.A.J., IETSWAART, J.H. \& ERNST, W.H.O. 1994. Mycorrhizal infection of an agrostis-capillaris population on a copper contaminated soil. Plant and Soil 158:83-89.

HARLEY, J.L. 1989. The significance of mycorrhiza. Mycological Research 92:129-139.

JASPER, D.A., ABBOT, L.K. \& ROBSON, A.D. 1994. Soil disturbance in native ecosystems - The decline and recovery of infectivity of VA mycorrhizal fungi. In Mycorrhizas in ecossystems. (D.J. Read, D.H. Lewis, A.H. Fitter \& I.J. Alexander, eds.). CAB International, Cambridge, p.151-155.

JENKINS, W.R. 1964. A rapid centrifugal-flotation technique for separating nematodes from soil. Plant Disease Report 48:692.

LIU, R.J. \& LUO, X.S. 1994. A new method to quantify the inoculum potential of arbuscular mycorrhizal fungi. New Phytologist 128:89-92.

MAIA, L.C. \& TRUFEM, S.F.B. 1990. Fungos micorrízicos vesículo-arbusculares em solos cultivados no Estado de Pernambuco, Brasil. Revista Brasileira de Botânica 13:89-95.

MELO, A.M.Y., MAIA, L.C. \& MORGADO, L.B. 1997. Fungos micorrízicos arbusculares em bananeiras cultivadas no vale do submédio São Francisco. Acta Botanica Brasilica 11:115-121.

MERRYWEATHER, J.W. \& FITTER, A. 1998. The arbuscular mycorrhizal fungi of Hyacinthoides non-scripta. II. Seasonal and spatial patterns of fungal populations. New Phytologist 138:131-142.

NOGUEIRA, A.V. 1996. As micorrizas e o excesso de metais. In Avanços em fundamentos e aplicação de micorrizas (J.O. Siqueira, ed.). UFLA/DCS e DCF, Lavras, p.135-174. 
PHILLIPS, J.M. \& HAYMAN, D.S. 1970. Improved procedures for clearing roots and staining parasitic and vesicular arbuscular mycorrhizal fungi for rapid assessment of infection. Transactions of the British Mycological Society 55:158-161.

ROSENDAHL, S., SEN, R., HEPPER, C.M. \& AZCON-AGUILAR, C. 1989. Quantification of three vesicular-arbuscular mycorrhizal fungi Glomus spp. in roots of leek Allium porrum on the basis of activity of diagnostic enzymes after polyacrylamide gel electrophoresis. Soil Biology and Biochemistry 21:519-522.

SIEVERDING, E. 1991. Vesicular-arbuscular mycorrhiza management in tropical agrosystems. Deutsche Gesellschaft für Technische Zusammenarbeit (GTZ), Eschborn, Germany.

SMITH, S.E. \& READ, D.J. 1997. Mycorrhizal Symbiosis. 2 ed. Academic Press, London.
SOUZA, F.A. \& SILVA, E.M.R. 1996. Micorrizas arbusculares na revegetação de áreas degradadas. In Avanços em fundamentos e aplicação de micorrizas (J.O. Siqueira, ed.). UFLA/DCS e DCF, Lavras, p.255-290.

STATSOFT. 1995. Statistic for Windows 95. V. 1. General Convertions and Statistics 1. Statsoft Incorporation, Oklahoma, v.1.

TRUFEM, S.F.B. 1996. Methods for the assessment of diversity in mycorrhizae. In Biodiversity in Brazil: a first approach. (C.E. Bicudo \& N.A. Menezes, eds.). CNPq, São Paulo, p.49-63.

VALSECCHI, G., GIGLIOTI, C. \& FARINI, A. 1995. Microbial biomass, activity, and organic matter accumulation in soils contamined with heavy metals. Biology and Fertility of Soils 20:253-259.

WILSON, J.M. \& TRINICK, M.J. 1982. Factors affecting the estimation of numbers of infective propagules of vesicular arbuscular mycorrhizal fungi by the Most Probable Number method. Australian Journal of Soil Research 21:73-81. 